\title{
Expressed emotion, medication adherence and association with disease prognosis in patients with schizophrenia at Teaching Hospital, Anuradhapura
}

\author{
A Ellepola, CA Abayaweera
}

\section{Abstract \\ Background}

High expressed emotion is a robust predictor of relapse in schizophrenia. In spite of significant involvement of the family in caring for mentally ill in Sri Lanka, studies on expressed emotion in Sri Lanka are limited.

\section{Aims}

To explore associations between high expressed emotion, treatment adherence, and the number of relapses needing admission among patients diagnosed to have schizophrenia who were managed at Teaching Hospital, Anuradhapura, Sri Lanka.

\section{Methods}

A cross sectional study was conducted among a sample of 170 patients with schizophrenia and their primary caregivers. The Level of Expressed Emotion questionnaire was used to assess for high expressed emotion.

\section{Results}

Females constituted $52 \%$ of the participants. Mean age was 40 years. Most were married, unemployed and had poor treatment adherence. Low expressed emotion was reported by $58 \%$ of the study population. The primary caregiver was most often a married female, with a mean age 51 years. Patients who experienced high expressed emotion and had poor treatment adherence had a higher number of relapses $(p<0.01)$. Expressed emotion, illness duration and compliance were independent risk factors for relapse $(p<0.05)$. Gender and living with primary caregiver did not significantly predict relapse.

\section{Conclusions}

The findings of this study were consistent with previous research findings. High expressed emotion, mainly due to hostile attitudes towards illness, and poor medication adherence were associated with frequency of relapses in a group of Sri Lankan patients with schizophrenia. Further research is needed to explore cultural and geographic differences.

Key words: Expressed emotions, treatment adherence, schizophrenia

SL J Psychiatry 2020; 11(1): 20-25

\section{Introduction}

Expressed emotion (EE) describes the caregiver's attitudes and behaviour towards a person with a mental illness and is comprised of criticism, hostility and emotional overinvolvement (1). High EE has a direct association with recurrence of wide range of mental illness, especially schizophrenia (2). Significant behavioural deterioration has been reported in patients with schizophrenia who live with even minimally hostile relatives (2). Evidence shows that patients with schizophrenia returning home from the hospital to live with a high EE family are more than twice as likely to relapse compared to patients who return home to families with low EE $(1,3,4)$.

However, only few studies have studied this aspect in Asia (6-13). A study from North India confirmed the association between relapse of schizophrenia and high EE in the family, but only the association between hostility and relapse was statistically significant (9). Similar evidence has also emerged from Japan and Pakistan, where high EE was found to be an important predictor of relapse, with criticism and hostility being the main 
contributory components $(10,13)$. This suggests that the expression of anger in the form of hostility is relatively unmodified by cultural factors and has a similar effect on patients with schizophrenia regardless of their cultural background (9). This may also indicate that the role of emotional over-involvement (EOI) in the prediction of relapse may vary with the cultural background of the patient and caregiver (10).

Family members play a pivotal role in management of mentally ill individuals in Sri Lanka. But evidence on associations between the caregiver's attitude and behaviour towards these individuals and relapse of the illness in Sri Lanka, is limited. Therefore, the aim of the current study was to explore the relationship (if any) between EE, adherence and relapses in Sri Lankan patients with schizophrenia, presenting to Teaching Hospital, Anuradhapura.

\section{Methods}

This was a cross-sectional descriptive study, conducted in the psychiatry wards of Teaching Hospital, Anuradhapura. Convenience sampling was used for participant selection. The sample size of 169 was calculated using the Cochran's formula, $\mathrm{n}_{0}=\mathrm{Z}^{2} \mathrm{pq} / \mathrm{e}^{2}$; where $\mathrm{e}=$ the desired level of precision (i.e., the margin of error) was at $1.5 \%$, $\mathrm{p}=$ the (estimated) proportion of the population which has schizophrenia (1\%), q = 1-p, and the $\mathrm{z}$-value were as found in the $\mathrm{Z}$ table, with a $95 \%$ confidence level of 1.96 (14).

Participants were recruited into the study if they had been diagnosed to have schizophrenia by a consultant psychiatrist, according to the ICD-10 Classification of Mental and Behavioural Disorders diagnostic criteria, were admitted to the psychiatry ward with a relapse, and were aged 18 years or above (15). Remission was determined on discharge by a consultant psychiatrist (AE) using the eight-item positive and negative syndrome scale criteria for remission, with a score of three or less (16). Patients with co-morbid learning disability, those with bipolar affective disorder, schizoaffective disorder, dementia, and patients living on their own without family members or guardians, were excluded from the study.

Of the 180 consecutive patients who were eligible to be included in the study, 170 patients and their primary caregivers voluntarily participated in the study, over four months duration. A questionnaire designed for the study was used to gather socio-demographic information and details on the number of relapses. Adherence to medication was assessed by pill count and clinical assessment by the psychiatrist, using the clinician administered brief adherence rating scale $(27,28)$. An adherence level of $80 \%$ or more was considered as satisfactory adherence, with a level of less than $80 \%$ being considered as non-adherence (28-30).
A questionnaire-based survey was conducted among participant patients after they had recovered from the acute relapse but prior to discharge from hospital, and their relatives. The survey was conducted using the client and relative versions of the Level of Expressed Emotion (LEE) questionnaire (19). The LEE scale is a 60-item selfreported questionnaire with four subscales for intrusiveness, emotional response, attitude toward illness and tolerance and expectations respectively (19). The patient version of this scale has been shown to predict rehospitalization at two years and five years for patients with schizophrenia (20). Even though the LEE scale is validated in English and other languages such as Mandarin (17), it has not yet been translated or validated in Sinhala or Tamil. Therefore both the client and relative versions of the LEE scale were translated into the Sinhala and Tamil languages, with cross-cultural adaption prior to use in this study $(31,32,34)$. The translated scales were back-translated into English and compared with the original scale for accurate translation of original content. Content and face validity was obtained from a panel of 6 experts with the Delphi method (33). Only minor inconsistencies were noted, resulting in minor revisions and only two rounds were needed. Expert opinion was also sought for cultural adaptation of the items in the scale and a cut off score of 30 was considered for this study. Concerns regarding items in the scale as to whether the items were relevant, precise and understandable were considered, and after discussion a few semantic and conceptual changes were made, and resulting in the final translated version. A pilot study was conducted among 21 healthcare personnel to strengthen the semantic and content equivalence $(32,34)$.

\section{Ethics}

Participant information sheets and one to one information sessions were used to inform the participants regarding the study. Only participants who gave written informed consent were included in the study. Patients were recruited to the study when their acute relapse had improved, prior to discharge from hospital. Participants were invited to complete the client and relative versions of LEE scale separately and confidentially, to minimize response bias.

Ethical clearance was obtained from the Ethics Committee, National Institute of Mental Health (NIMH), Angoda, Sri Lanka, and permission to conduct the study was obtained from the administrative director, Teaching Hospital, Anuradhapura, Sri Lanka. All data was stored securely and confidentially.

\section{Analysis}

Data was analysed using SPSS software, Version 22. A two-way ANOVA was conducted to examine the effects 
of adherence and level of EE on number of relapses. Data is presented as mean \pm standard deviation, unless otherwise specified.

\section{Results}

Of the total 170 participants, $48.2 \%(n=82)$ were male (Table 1). Amajority (72.3\%) was between 21-50 years of age. Most males were between 21-30 years (25.6\%), while a majority of females were between 31-40 years (31.81\%). Many were living with their primary caregiver (74\%), with a mean contact duration of $10( \pm 6.19)$ hours during weekdays and 23 ( \pm 13.50 ) hours during weekends. The main primary caregiver was often married (81\%), female (60.6\%), was the mother (29\%) or spouse (27\%) and had a mean age of $51( \pm 13.21)$ years.

Table 1. Demographic characteristics of patients and caregivers included in the study

\begin{tabular}{|c|c|c|c|c|c|c|}
\hline \multicolumn{2}{|l|}{ Patient characteristics } & \multirow{2}{*}{$\begin{array}{l}\text { Mean } \\
40.10\end{array}$} & \multirow{2}{*}{$\begin{array}{c}\text { SD } \\
\pm 13.39\end{array}$} & \multirow{2}{*}{$\begin{array}{l}\text { Range } \\
18-83\end{array}$} & \multirow{2}{*}{$\begin{array}{l}n \\
82 \\
88\end{array}$} & \multirow{2}{*}{$\begin{array}{r}\% \\
48.2 \\
51.8\end{array}$} \\
\hline $\begin{array}{l}\text { Age (years) } \\
\text { Gender }\end{array}$ & $\begin{array}{l}\text { Male } \\
\text { Female }\end{array}$ & & & & & \\
\hline Marital Status & $\begin{array}{l}\text { Married } \\
\text { Single/Unmarried } \\
\text { In a relationship } \\
\text { Separated/Divorced } \\
\text { Widowed }\end{array}$ & & & & $\begin{array}{l}81 \\
60 \\
06 \\
17 \\
06\end{array}$ & $\begin{array}{c}47.6 \\
35.3 \\
3.5 \\
10 \\
3.5\end{array}$ \\
\hline Occupational Status & $\begin{array}{l}\text { Employed } \\
\text { Unemployed }\end{array}$ & & & & $\begin{array}{l}55 \\
115\end{array}$ & $\begin{array}{l}32.4 \\
67.6\end{array}$ \\
\hline Ethnicity & $\begin{array}{l}\text { Sinhala } \\
\text { Tamil } \\
\text { Muslim/Moor } \\
\text { Burgher }\end{array}$ & & & & $\begin{array}{l}159 \\
01 \\
10 \\
0\end{array}$ & $\begin{array}{r}93.5 \\
0.6 \\
5.9 \\
0\end{array}$ \\
\hline Level of Income & $\begin{array}{l}<10000 \\
10000-25000 \\
25000-50000 \\
>50000\end{array}$ & & & & $\begin{array}{l}52 \\
73 \\
37 \\
08\end{array}$ & $\begin{array}{r}30.6 \\
42.9 \\
21.8 \\
4.7\end{array}$ \\
\hline Level of Education & $\begin{array}{l}\text { None/ }<\text { Grade } 5 \\
\text { Grade } 5 \text { to } 11 \\
\text { Ordinary Level } \\
\text { Advanced Level } \\
\text { Graduate }\end{array}$ & & & & $\begin{array}{l}39 \\
59 \\
50 \\
15 \\
07\end{array}$ & $\begin{array}{r}22.9 \\
34.7 \\
29.4 \\
8.8 \\
4.1\end{array}$ \\
\hline Primary Caregiver Charac & tics & Mean & SD & Range & $\mathrm{n}$ & $\%$ \\
\hline $\begin{array}{l}\text { Age (years) } \\
\text { Gender }\end{array}$ & $\begin{array}{l}\text { Male } \\
\text { Female }\end{array}$ & 50.62 & \pm 13.21 & $22-80$ & $\begin{array}{l}67 \\
103\end{array}$ & $\begin{array}{l}39.4 \\
60.6\end{array}$ \\
\hline Primary Caregiver & $\begin{array}{l}\text { Mother } \\
\text { Father } \\
\text { Brother } \\
\text { Sister } \\
\text { Spouse } \\
\text { Friend } \\
\text { Other }\end{array}$ & & & & $\begin{array}{l}50 \\
11 \\
23 \\
23 \\
45 \\
07 \\
11\end{array}$ & $\begin{array}{r}29.4 \\
6.5 \\
13.5 \\
13.5 \\
26.5 \\
4.1 \\
6.5\end{array}$ \\
\hline $\begin{array}{l}\text { Living with Primary } \\
\text { Caregiver }\end{array}$ & $\begin{array}{l}\text { Yes } \\
\text { No }\end{array}$ & & & & $\begin{array}{l}126 \\
44\end{array}$ & $\begin{array}{l}74.1 \\
25.9\end{array}$ \\
\hline Marital Status & $\begin{array}{l}\text { Married } \\
\text { Single } \\
\text { Divorced/Separated } \\
\text { Widowed } \\
\text { In a relationship }\end{array}$ & & & & $\begin{array}{l}138 \\
09 \\
07 \\
10 \\
06\end{array}$ & $\begin{array}{r}81.2 \\
5.3 \\
4.1 \\
5.9 \\
3.5\end{array}$ \\
\hline Number of contact hours & $\begin{array}{l}\text { Weekdays } \\
\text { Weekends }\end{array}$ & $\begin{array}{l}9.64 \\
22.92\end{array}$ & $\begin{array}{l} \pm 6.19 \\
\pm 13.50\end{array}$ & $\begin{array}{l}0-24 \\
0-48\end{array}$ & & \\
\hline
\end{tabular}


The mean number of lifetime relapses experienced by study participants was $6.18( \pm 5.72)$ and the mean number of days between relapses was $872.31( \pm 762.22)$. Of the patients $38.8 \%(n=66)$ had satisfactory adherence to treatment, while the remainder had poor or nonadherence. The mean duration of illness was 12.02 $( \pm 9.43)$ years. Low EE was seen in $58.2 \%(n=99)$ of patients' families.

The mean number of relapses for low EE with satisfactory or poor treatment adherence was $3.38 \pm 3.10$ and $4.60 \pm$ 3.70 , respectively. The mean number of relapses for high EE with satisfactory or poor adherence was $5.29 \pm 5.27$ and, $10.26 \pm 6.77$, respectively.

There was a significant association between medication adherence, level of $\mathrm{EE}$, and the number of relapses $(F(1,166)=33.967, p<0.0005$, partial $\eta 2=0.170)$. The Bonferroni adjustment (accepted at a level of $\mathrm{p}<.005$ ), indicated a statistically significant difference in the mean number of relapses for those with high EE and poor adherence (5.67 (95\% CI, 3.75 to7.59), $\mathrm{F}(1,166)=$ 33.967, $\mathrm{p}<0.0005$, partial $\eta 2=0.170)$, but not for those with low EE (1.90 (95\% CI, -1.03 to 4.83), F (1, 166) $=1.637, \mathrm{p}=0.2$, partial $\eta 2=0.010)$.

Multiple regression was carried out to determine if EE predicted relapse. According to this model, EE showed a statistically significantly prediction of the number of relapses $\left(F(4,165)=17.224, p<.0005\right.$, adj. $\left.R^{2}=.28\right)$ (Table 2). Out of the four constructs of EE, only attitudes towards the patient added statistically significantly to this prediction $(\mathrm{p}<.05$, Table 2$)$.

\begin{tabular}{|c|c|c|c|}
\hline Variable & B & $\mathrm{SE}_{\mathrm{B}}$ & ß \\
\hline Intercept & .193 & 1.320 & \\
\hline Intrusiveness & .327 & .189 & .128 \\
\hline Emotional Response & -.063 & .168 & -.051 \\
\hline Attitude towards patient ${ }^{*}$ & .732 & .205 & .599 \\
\hline Total score EE & .117 & .023 & .297 \\
\hline
\end{tabular}

Note. ${ }^{*} \mathrm{p}<0.05 ; \mathrm{B}=$ unstandardized regression coefficient; $\mathrm{SE}_{\mathrm{B}}=$ standard error of the coefficient; $\beta=$ standardized coefficient

Multiple regressions were also carried out to determine if gender, illness duration, adherence or living with the primary caregiver predicted relapse. Results showed a statistically significant prediction of number of relapses $\left(\mathrm{F}(5,164)=41.72, \mathrm{p}<0.0005 \mathrm{adj} . \mathrm{R}^{2}=0.546\right)$. This model showed that illness duration and treatment adherence added statistically significantly to the prediction of relapse, ( $<<0.05$ ), whereas gender and living with the primary caregiver did not statistically significantly predict relapse (Table 3).

\begin{tabular}{|c|c|c|c|}
\hline Variable & B & $\mathrm{SE}_{\mathrm{B}}$ & ß \\
\hline Intercept & -4.380 & 1.539 & \\
\hline Adherence $^{*}$ & 1.705 & .660 & .146 \\
\hline Illness Duration* & .332 & .033 & .547 \\
\hline Gender & .348 & .598 & .030 \\
\hline $\begin{array}{l}\text { Living with primary } \\
\text { care giver }\end{array}$ & -.162 & .376 & -.023 \\
\hline
\end{tabular}

Note. ${ }^{*} \mathrm{p}<0.05 ; \mathrm{B}=$ unstandardized regression coefficient; $\mathrm{SE}_{\mathrm{B}}=$ standard error of the coefficient; $\beta=$ standardized coefficient

\section{Discussion}

In this study, a majority of participants had experienced low EE (58\%), which is in contrast to findings from other countries, such as Japan and Pakistan $(10,13)$. However similar low experience of $\mathrm{EE}$ has been reported from some other countries such as Bali (11). These differences in the prevalence of the level of EE may be due to differences in socio-cultural backgrounds, and warrants further detailed exploration.

In this study, the mean relapse rate was significantly higher among patients experiencing high EE and poor adherence, compared to patients with low EE and good adherence. Expressed emotions, illness duration and poor treatment adherence statistically significantly predicted relapse. However, gender and living with primary caregiver did not significantly predict relapse. These findings are consistent with previous evidence that high EE significantly predicted relapses of schizophrenia compared to low EE (1, 3-4). Further, our findings are compatible with other cross-cultural research evidence, from Eastern Europe, America and Asia and other South Asian countries such as India (9-13). Our findings suggest that hostile attitudes towards mental illness, and towards patients, are relatively unmodified by diverse cultural factors (9).

\section{Limitations}

Although this study sample represents the Anuradhapura district, the results do not represent Sri Lanka as a whole. Further, sampling was done using convenience sampling, which makes the findings less generalizable. 
Stigma and concerns that participants may be judged by their answers, may have influenced the responses in the self-administered questionnaires. However, attempts were made to minimize this limitation by informing participants ahead about the reasons for data collection, and by administering the questionnaires separately and confidentially to patients and relatives.

The LEE scale has not been translated or validated for use in Sri Lanka, in either Sinhalese or Tamil. The investigators took steps to minimize errors by translating, back translating, getting expert opinion and by conducting a pilot study for face and content validity and cultural adaption.

\section{Conclusions}

This study confirms the long held view that relapse of schizophrenia is associated with high expressed emotions, particularly hostile attitude towards the illness and patient, together with poor treatment adherence. This highlights the need for family psycho-education and family interventions in Sri Lanka to reduce high EE among primary caregivers, in order to reduce relapse and readmissions in patients with schizophrenia. The manner in which cultural and geographic differences could contribute to high EE is worth exploring further. Future studies should target wider, more representative sample distribution to enable generalization of the findings to the whole country.

\section{Acknowledgments}

The authors gratefully acknowledge the support given by Dr. Chandran Partheepan and Dr. N Liyanarachchi for this research project.

\section{Conflicts of interest}

None declared

\section{A Ellepola, Consultant Psychiatrist, Teaching Hospital, Anuradhapura, Sri Lanka}

CA Abayaweera, Registrar in Psychiatry, Teaching Hospital, Anuradhapura, Sri Lanka

Corresponding author: A Ellepola

Email: anu.ellepola@gmail.com

http://orcid.org/0000-0001-9699-2777

\section{References}

1. Hooley JM, Parker HA. Measuring expressed emotion: An evaluation of the shortcuts. J Fam Psychol. 2006; 20(3): 386-96.

2. Brown GW, Monck EM, Carstairs GM, Wing JK. Influence of Family Life on the Course of Schizophrenic Illness. J Epidemiol Community Health. 1962; 16(2): 55-68.

3. Butzlaff RL, Hooley JM. Expressed Emotion and Psychiatric Relapse: A Meta-analysis. Arch Gen Psychiatry. 1998; 55(6): 547.

4. Vaughn CE, Leff JP. The influence of family and social factors on the course of psychiatric illness. A comparison of schizophrenic and depressed neurotic patients. Brit J Psychiatry. 1976; 129(2): 125-37.

5. King S, Dixon M. Expressed Emotion and Relapse in Young Schizophrenia Outpatients. Schizophr. Bull. 1999; 25(2): 377-86.

6. Marom S. Expressed Emotion: Relevance to Rehospitalization in Schizophrenia Over 7 Years. Schizophr Bull. 2005; 31(3): 751-8.

7. Weintraub MJ, Hall DL, Carbonella JY, Weisman de Mamani A, Hooley JM. Integrity of Literature on Expressed Emotion and Relapse in Patients with Schizophrenia Verified by a $p$-Curve Analysis. Fam Process. 2017; 56(2): 436-44.

8. Cechnicki A, Bielanska A, Hanuszkiewicz I, Daren A. The predictive validity of Expressed Emotions (EE) in schizophrenia. A 20-year prospective study. J. Psychiatr. Res. 2013; 47(2): 208-14.

9. Leff J, Wig N, Menon D, Bedi H, Kuipers L, Ghosh A, et al. Expressed Emotion and Schizophrenia in North India. Brit J Psychiat. 1987; 151(2): 166-173.

10. Tanaka S, Mino Y, Inoue S. Expressed Emotion and the Course of Schizophrenia in Japan. Br J Psychiatry. 1995; 167(06): 794-8.

11. Kurihara T, Kato M, Tsukahara T, Takano Y, Reverger R. The low prevalence of high levels of expressed emotion in Bali. Psychiatry Res. 2000; 94(3): 229-38.

12. Roseliza-Murni A, Oei T, Fatimah Y, Asmawati D. Schizophrenia relapse in Kuala Lumpur, Malaysia: Do relatives' expressed emotion and personality traits matter?. Compr Psychiatry. 2014; 55(1): 188-98.

13. Sadiq S, Suhail K, Gleeson J, Alvarez-Jimenez M. Expressed emotion and the course of schizophrenia in Pakistan. Soc Psychiatry Psychiatr Epidemiol. 2017; 52(5): 587-93.

14. Charan, J. and Biswas, T. How to calculate sample size for different study designs in medical research?. Indian Journal of Psychological Medicine, 2013; 35(2): 121. 
15. The ICD-10 classification of mental and behavioural disorders. Geneva: World Health Organization; 2003.

16. Opler M, Yang L, Caleo S, Alberti P. Statistical validation of the criteria for symptom remission in schizophrenia: Preliminary findings. BMC Psychiatry. 2007;7(1).

17. Chien W, Chan Z, Chan S, Yip L, Ip G. Psychometric properties of a Chinese version of the Level of Expressed Emotion scale and expressed emotion of family members perceived by patients with severe mental illness. Hong Kong Med J 2016; 22(Suppl 6): S28-34.

18. Health.gov.lk. (2018). [online] Available at: http:// www.health.gov.lk/moh_final/english/public/elfinder/files/ publications/AHB/2017/AHS\%202016.pdf [Accessed 24 Dec. 2018].

19. Cole JD, Kazarian SS. The level of expressed emotion scale: A new measure of expressed emotion. J. Clin. Psychol (988; 44(3): 392-397. doi:10.1002/10974679(198805) 44:3<392::aid-jclp2270440313>3.0.co;2-3

20. Cole JD, Kazarian SS. Predictive validity of the level of expressed emotion (LEE) scale: Readmission follow-up data for 1, 2, and 5-year periods. J. Clin. Psychol. 1993; 49(2): 216-218. doi:10.1002/1097-4679(199303) 49:2<216::aid-jclp2270490214>3.0.co;2-g

21. Lader M. What is relapse in schizophrenia? Int. Clin. Psychopharmacol. 1995;9:5-10. doi:10.1097/00004850199501005-00002.

22. Haynes RB. Introduction. In: Haynes RB, Taylor DW, Sackett DL, editors. Compliance in Health Care. Baltimore, Md: Johns Hopkins University Press; 1979. pp. 1-18. Available from: http://www.sciepub.com/reference/ 269238

23. Buchanan A. Compliance with treatment in schizophrenia. London: Routledge; 2013.

24. Cohen J, Cohen P, West SG, Aiken LS. Applied multiple regression/correlation analysis for the behavioral sciences (3rd ed.). Mahwah, NJ: Lawrence Erlbaum Associates. 2003
25. Jaccard, J. Interaction effects in factorial analysis of variance. Thousand Oaks, CA: Sage Publications.; 1998.

26. Maxwell SE, Delaney HD. Designing experiments and analyzing data: A model comparison perspective (2nd ed.). New York, NY: Psychology Press; 2004.

27. Byerly M, Nakonezny P, Rush A. The Brief Adherence Rating Scale (BARS) validated against electronic monitoring in assessing the antipsychotic medication adherence of outpatients with schizophrenia and schizoaffective disorder. Schizophr. Res. 2008; 100(1-3): 60-9.

28. Lam W, Fresco P. Medication Adherence Measures: An Overview. Biomed Res. Int. 2015; 2015: 1-12.

29. Ho P, Bryson C, Rumsfeld J. Medication Adherence. Circulation. 2009; 119(23): 3028-35.

30. van Onzenoort H, Verberk W, Kessels A, Kroon A, Neef C, van der Kuy P et al. Assessing Medication Adherence Simultaneously by Electronic Monitoring and Pill Count in Patients With Mild-to-Moderate Hypertension. Am. J. Hypertens. 2010; 23(2): 149-54.

31. Beaton D, Bombardier C, Guillemin F, Ferraz M. Guidelines for the Process of Cross-Cultural Adaptation of Self-Report Measures. Spine. 2000;25(24):3186-3191. doi:10.1097/00007632-200012150-00014

32. Ballangrud R, Husebø SE, Hall-Lord, ML. Cross-cultural validation and psychometric testing of the Norwegian version of the TeamSTEPPS ${ }^{\circledR}$ teamwork perceptions questionnaire. BMC Health Serv Res 2017; .17: 799 https://doi.org/10.1186/s12913-017-2733-y

33. Grime M, Wright G. Delphi Method. Wiley StatsRef: Statistics Reference Online. 2016:1-6. doi:10.1002/ 9781118445112.stat07879

34. Sousa VD, Rojjanasrirat W. Translation, adaptation and validation of instruments or scales for use in cross-cultural health care research: a clear and user-friendly guideline. $\mathrm{J}$ Eval Clin Pract. 2011; 17(2): 268-74. https://doi.org/ 10.1111/j.1365-2753.2010.01434.x. 